$(48.6 \%)$ were the most vulnerable group of population. Falls $(48.9 \%)$ were the most common cause of neurotraumatic accidents. Other injuries occur at workplace, home and in the community.

Conclusion Our review suggests that injuries and violence pose a big problem; road traffic accidents make the most part of it.

\title{
0053 INJURIES AND VIOLENCE IN NEPAL: A REVIEW
}

J S Kumar*, S Suvash Correspondence: Kathmandu Medical College, Department of Community Medicine Kathmandu Medical College Baburam Acharya Sadak Sinamangal, PO Box 21266 Kathmandu Nepal, 44600, Nepal

\subsection{6/ip.2010.029215.53}

Nepal lacks sufficient data on injury and violence. Studies have been done in different regions but there is not a nationwide study on this topic. So, we've designed this review to get a cumulative picture of injury and violence status in Nepal.

Methodology We searched Medline database, Google scholar database and also all the national medical journals for relevant studies on injuries and violence. Our eligibility criteria included studies done in Nepal, evaluating the incidence of different forms of injuries and their causes and effects. We excluded case reports and reviews. Though we found 120 articles through our literature search, we included only 23 studies that met our eligibility criteria. We made cumulative analysis wherever possible.

Results All the studies were descriptive. In overall, the incidence of injuries was twice as common in male as in female (Male:Female $=2 \cdot 1: 1$ ). The economically active population between 20 and 50 years of age was mostly involved in injuries. Road traffic injuries were the most common form of injuries, most of which (42.5\%) involved motorcycles. Pedestrians 